\title{
Neural plasticity lessons from disorders of consciousness
}

\author{
Athena Demertzi, Caroline Schnakers, Andrea Soddu, Marie-Aurélie Bruno, Olivia Gosseries, Audrey \\ Vanhaudenhuyse and Steven Laureys*
}

Coma Science Group, Cyclotron Research Centre and Neurology Department, Sart Tilman, University and University Hospital of Liège, Liège, Belgium

\section{Edited by:}

Morten Overgaard, Aarhus University, Aarhus University Hospital, Denmark

\section{Reviewed by:}

Ryota Kanai, University College

London, UK

Jessica Saenger, Heinrich-Heine-

University of Düsseldorf, Germany

${ }^{*}$ Correspondence:

Steven Laureys, Cyclotron Research

Center, Allée du 6 août No. 8, Sart

Tilman B30, 4000 Liège, Belgium.

e-mail:steven.laureys@ulg.ac.be
Communication and intentional behavior are supported by the brain's integrity at a structural and a functional level. When widespread loss of cerebral connectivity is brought about as a result of a severe brain injury, in many cases patients are not capable of conscious interactive behavior and are said to suffer from disorders of consciousness (e.g., coma, vegetative state/ unresponsive wakefulness syndrome, minimally conscious states). This lesion paradigm has offered not only clinical insights, as how to improve diagnosis, prognosis, and treatment, but also put forward scientific opportunities to study the brain's plastic abilities. We here review interventional and observational studies performed in severely brain-injured patients with regards to recovery of consciousness. The study of the recovered conscious brain (spontaneous and/ or after surgical or pharmacologic interventions), suggests a link between some specific brain areas and the capacity of the brain to sustain conscious experience, challenging at the same time the notion of fixed temporal boundaries in rehabilitative processes. Altered functional connectivity, cerebral structural reorganization as well as behavioral amelioration after invasive treatments will be discussed as the main indices for plasticity in these challenging patients. The study of patients with chronic disorders of consciousness may, thus, provide further insights not only at a clinical level (i.e., medical management and rehabilitation) but also from a scientific-theoretical perspective (i.e., the brain's plastic abilities and the pursuit of the neural correlate of consciousness).

Keywords: neural plasticity, recovery, unresponsive wakefulness syndrome, vegetative state, minimally conscious state, consciousness, functional neuroimaging, deep brain stimulation
Thanks to last decades' technological advances, the study of consciousness has been under the scrutiny of neuroscientific research. The notion that consciousness is supported by and emerged from the brain is well-documented by clinical cases of neurological patients suffering from disorders of consciousness (DOC): in coma, patients are unable to be awakened and hence show no awareness of themselves and of their environment; in the vegetative state (VS) now called unresponsive wakefulness syndrome (UWS; Laureys et al., 2010) there is a dissociation between arousal which is preserved (i.e., clinically evident by eyes opening) and awareness which is abolished (Jennett and Plum, 1972). The recently defined minimally conscious state (MCS) describes patients who show fluctuating signs of awareness but remain unable to communicate (Giacino et al., 2002). Through this lesion paradigm we have the opportunity not only to better understand the neural correlates of consciousness (Tononi and Laureys, 2009) but also to gain insight about the brain's plastic abilities (Laureys et al., 2006a). In the present review, the study of neural plasticity is approached via neurological evidence coming from neuroimaging technologies, such as structural and functional magnetic resonance imaging (MRI), and positron emission tomography (PET), during pathological states and after recovery of consciousness. Altered cerebral functional connectivity, structural reorganization as well as behavioral amelioration after invasive and non-invasive treatments will be discussed as the main indices for plasticity in this challenging population (Figure 1).

\section{INTERVENTIONAL STUDIES DEEP BRAIN STIMULATION}

Deep brain stimulation (DBS) is an interventional surgical procedure which requires the implantation of microelectrodes in deep structures of the brain and the administration of low voltage electricity in these structures. Despite some sparse evidence that DBS may have some ameliorating effects on arousal in VS/UWS patients (Cohadon and Richer, 1993; Yamamoto et al., 2001), in general one cannot argue in favor of this treatment in the VS/UWS population. This is mainly due to the widespread underlying neuropathology of VS/UWS (Adams et al., 2000) which does not permit a straightforward functional re-integration after stimulating the structures of interest in these patients (Schiff and Fins, 2007).

In a more controlled experimental setting, where patients' selection was based on both their neuropathological status (i.e., specific information about the connections between the central thalamus, cerebral cortex, basal ganglia and other subcortical structures) and behavioral profile (i.e., exhibition of preserved arousal and fluctuating behavioral performance), a 38-year-old patient in a MCS more than 6 years after severe traumatic brain injury was selected for DBS treatment (Schiff et al., 2007). Up to the point of DBS treatment, the patient did not show any clinical amelioration despite a 2-year rehabilitation program. However, after applying DBS in bilateral central intralaminar thalamic nuclei (Figure 2), the patient showed stimulation-related improved levels of arousal, motor control, and interactive behavior as measured by neuropsychological testing during the DBS “on" periods. 


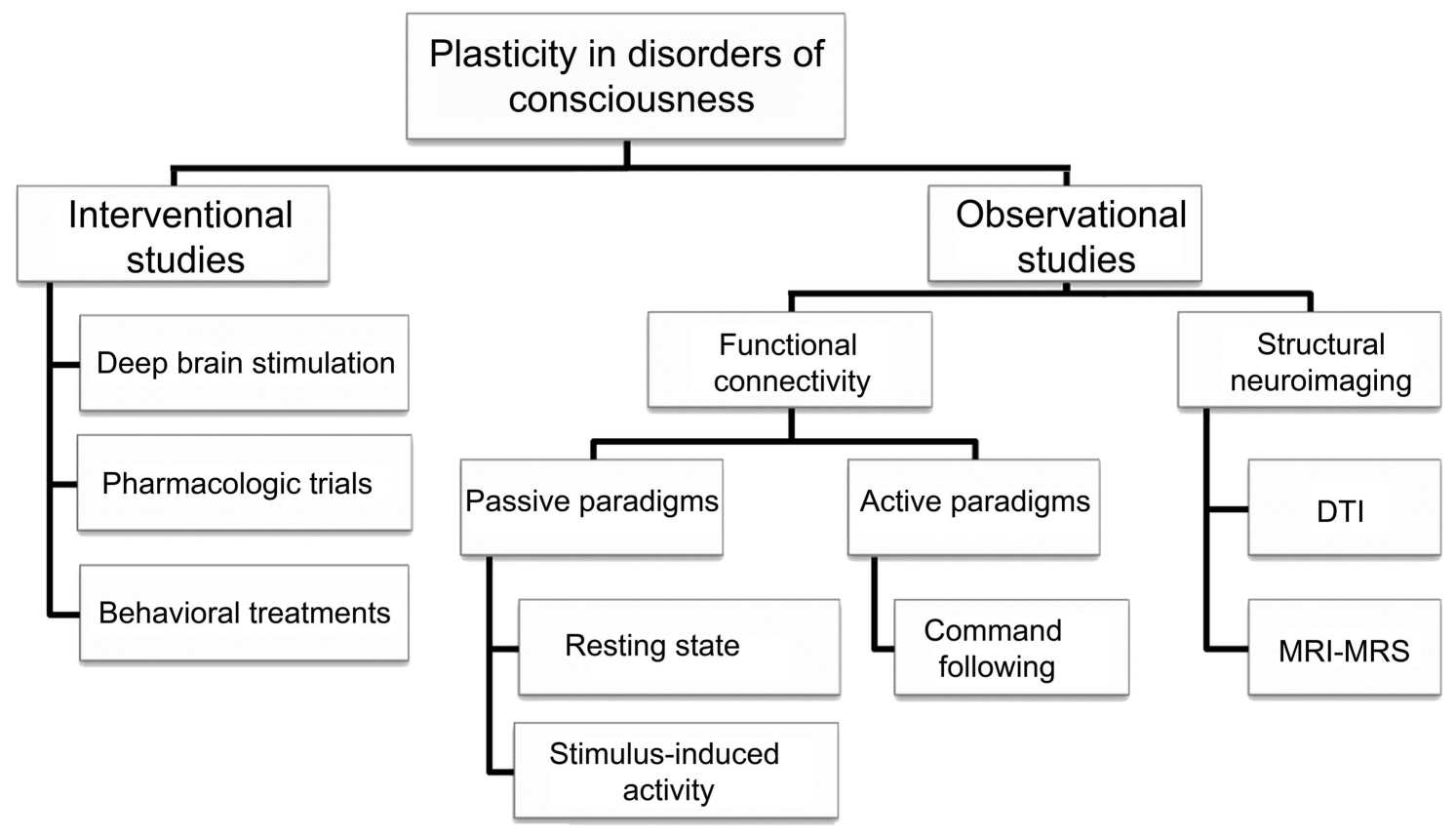

FIGURE 1 | Outline of studies dealing with plasticity issues in patients with disorders of consciousness. DTI, diffusion tensor imaging; MRI, magnetic resonance imaging; MRS, magnetic resonance spectroscopy.

The effects of DBS were attributed to the recruitable large-scale networks underlying the neuropathology of this MCS patient and were interpreted as a promotion of the patient's arousal regulation via the direct activation of the frontal cortical and basal ganglia systems, innervated by the stimulated thalamic neurons (Schiff et al., 2007; Schiff, 2010).

\section{PHARMACOLOGIC TRIALS}

Regarding the effects of pharmacologic trials in patients with DOC, generally speaking no satisfactory results exist (Laureys et al., 2006b). Small-scale pharmacologic studies indicate some exceptional respondents to either stimulant or depressant pharmacologic agents, but for whom no evidence-based recommendations can be made yet (Whyte et al., 2005; Demertzi et al., 2008).

Studies using amantadine, a mixed NMDA and dopaminergic agonist, showed a better outcome in traumatic patients with DOC (Whyte et al., 2005; Sawyer et al., 2008). In addition to behavioral amelioration, a recent PET study of chronic anoxic MCS showed a drug-related increase in fronto-parietal metabolism (Schnakers et al., 2008). Other dopaminergic agents which have been reported to lead to favorable functional outcome are levodopa and bromocriptine (Passler and Riggs, 2001). Clinical improvements has also been reported after administration of baclofen (GABA agonist administered mainly against spasticity; Taira and Hori, 2007) and zolpidem (non-benzodiazepine sedative drug that is used against insomnia in healthy people; for short review see Demertzi et al., 2008). The exact neuromodulating mechanism of these agents is not clear yet. A mesocircuit hypothesis, involving the corticothalamo-cortical system as well as projections of the basal ganglia to the central thalamus, has been recently proposed (Schiff, 2010). The dopaminergic agents are thought to either facilitate directly the mesio-frontal cortical neurons, which send excitatory projections to the central thalamus, or modulate the striatum leading to the restoration of the global dynamics of the cortico-thalamic system. On the other hand, zolpidem effects may be explained by a direct action at the level of the global pallidus interna which sends inhibitory projections to the central thalamus; this inhibitory effect could substitute for the normal inhibition of the globus pallidus from the striatum and hence lead to a more stabilized central thalamic activity (Schiff, 2010).

\section{NON-PHARMACOLOGIC INTERVENTIONS}

Non-pharmacologic interventions for DOC patients here refer to sensory stimulation techniques and physical therapy, which mainly aim at both preventing complications (i.e., contractures or pressure sore preventions) and/or at enhancing recovery. Sensory stimulation can refer to two types of approaches: multisensory stimulation or sensory regulation (Tolle and Reimer, 2003). The first expresses the principles of behaviorism and holds that enhanced environmental stimulation of the sensory systems is hoped to enhance synaptic re-innervations, whereas the second is based on the principles of information processing and focuses on the enhancement of selective attention by regulating the environment. Concerning physical therapy, there is some evidence that early (Oh and Seo, 2003) and increased intervention (Shiel et al., 2001) leads to better outcome.

\section{PERSPECTIVES}

The existing therapeutic nihilism in the field of DOC is currently getting challenged by recent data supporting that some DOC patients could benefit from some rehabilitative interventions (surgical, pharmacologic, or behavioral) reviewed above. Larger-scale 


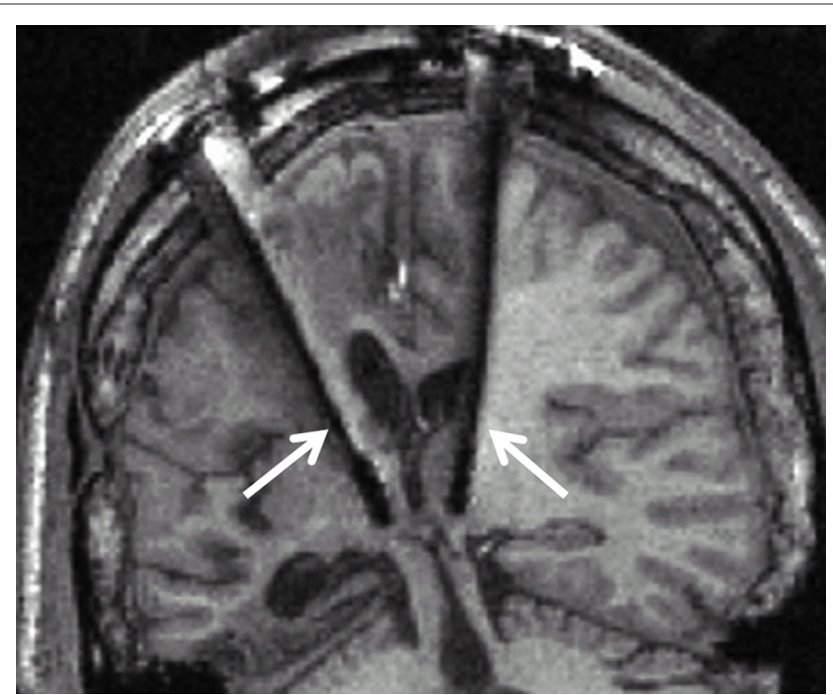

FIGURE 2 | Clinical setup of electrodes implementation in the central thalami bilaterally (white arrows) during deep brain stimulation. Adapted from Schiff et al. (2007).

studies with higher number of patients of various pathologies are ongoing, in order to better comprehend the underlying neuromodulatory effects of DBS and the induced neuroplastic changes in severely injured brains. Currently, the beneficial effects of the pharmacologic and non-pharmacologic approaches described above are not evidence-based and hence are not generally accepted by the medical community (for a systematic review see Lombardi et al., 2002). No unique hypothesis or theoretical framework (Laureys, 2005; Tononi and Laureys, 2009) can at present combine the temporal dynamics and pathophysiological mechanisms of all the aforementioned interventions (e.g., Pistoia et al., 2010) and many questions remain as to the precise mechanisms differentiating spontaneous from therapy-induced cerebral plasticity.

In the therapeutic management of patients with DOC, no "standards of care" do yet exist, mainly due to the limitation of their scientific evidence coming from small-scale studies under suboptimal or uncontrolled settings. Thus, no evidence-based recommendations can be made for a particular treatment option (Demertzi et al., 2008).

\section{OBSERVATIONAL STUDIES FUNCTIONAL CONNECTIVITY STUDIES Passive paradigms}

Functional neuroimaging does not only allow one to examine the functional segregation (i.e., localizing a function to a cerebral area) but also the functional integration (i.e., assessing the interaction between functionally segregated areas). Current analytical tools permit to assess the functional or effective connectivity between distant cerebral areas in functional imaging. Such analyses explain the activity in one cortical area in terms of an interaction between the influence of another area and some experimental condition (i.e., comparing data obtained during unconsciousness and after recovery). Functional connectivity is defined as the temporal correlation of a neurophysiological index (hemodynamic or metabolic) measured in different remote brain areas, whereas effective connectivity is defined as the influence one neural system exerts over another (Friston, 2002). Based on their experimental design, functional connectivity studies can be reduced to two main categories: passive (i.e., resting state, stimulus-induced activity) and active (i.e., mental task command following) paradigms (Bruno et al., 2010).

Using "resting state" fluorodeoxyglucose PET imaging, decreased global metabolic levels have been identified in VS/UWS patients, with no significant global metabolic resumption after recovery of consciousness. However, "functional disconnections" were identified in a large fronto-parietal network which exhibited regional metabolic restoration in long-range cortico-cortical (between latero-frontal and midline-posterior areas; Laureys et al., 1999) and cortico-thalamo-cortical (between non-specific thalamic nuclei and midline-posterior cortices) after recovery of consciousness from chronic VS/UWS (Laureys et al., 2000b; Figure 3). It is hence suggested that fronto-parietal network connectivity is critical in sustaining conscious awareness (Baars et al., 2003; Laureys et al., 2004a), as is also supported by evidence from studies on sensory perception in normal volunteers (Dehaene et al., 2006; Boly et al., 2007).

Positron emission tomography and fMRI studies have identified a "default mode network," defined as a set of areas, encompassing posterior cingulate/precuneus, anterior cingulate/ mesio-frontal cortex, and temporo-parietal junctions, which show more activity at rest than during attention-demanding tasks. Recent studies have shown that it is possible to reliably identify this network in the absence of any task, by resting state fMRI connectivity analyses in healthy volunteers (Boly et al., 2008b, 2009). This "default mode network" is considered to be involved in self-related processes (Mason et al., 2007; Buckner et al., 2008; Vanhaudenhuyse et al., 2011) but the functional significance of these spontaneous brain activity fluctuations in pathological states remain only partially understood. It has recently been shown that default mode connectivity decreases during propofol general anesthesia (Boveroux et al., 2010), sleep (Gould et al., 1999), and hypnotic state (McGeown et al., 2009; Demertzi et al., in press). In pathological impaired consciousness, resting state connectivity was shown to disappear in brain death (Boly et al., 2009) and to show a non-linear disintegration in pseudocoma or locked-in syndrome as compared to minimally conscious or relative to unconscious states (VS/UWS or coma; Vanhaudenhuyse et al., 2009; Figure 4).

Apart from resting state acquisitions, valuable information is gathered by studies observing the cerebral responses to external sensory stimulation. Using PET, stimulus-induced somatosensory (Laureys et al., 2002; Boly et al., 2008a) and auditory (Laureys et al., 2000a; Boly et al., 2004) activation protocols in VS/UWS patients have identified a cerebral response restricted to primary sensory cortices, whereas MCS patients demonstrated a stronger functional connectivity between sensory and fronto-parietal associative areas in these patients. These findings indicate that the presence of isolated neuronal groups that work in a module-like fashion, are not functionally sufficient for the conscious perception of the world and the generation of conscious behavior (Schiff et al., 2002). Additionally, stimuli with emotional valence like infant cries (Laureys et al., 2004b) or the patient's own name 

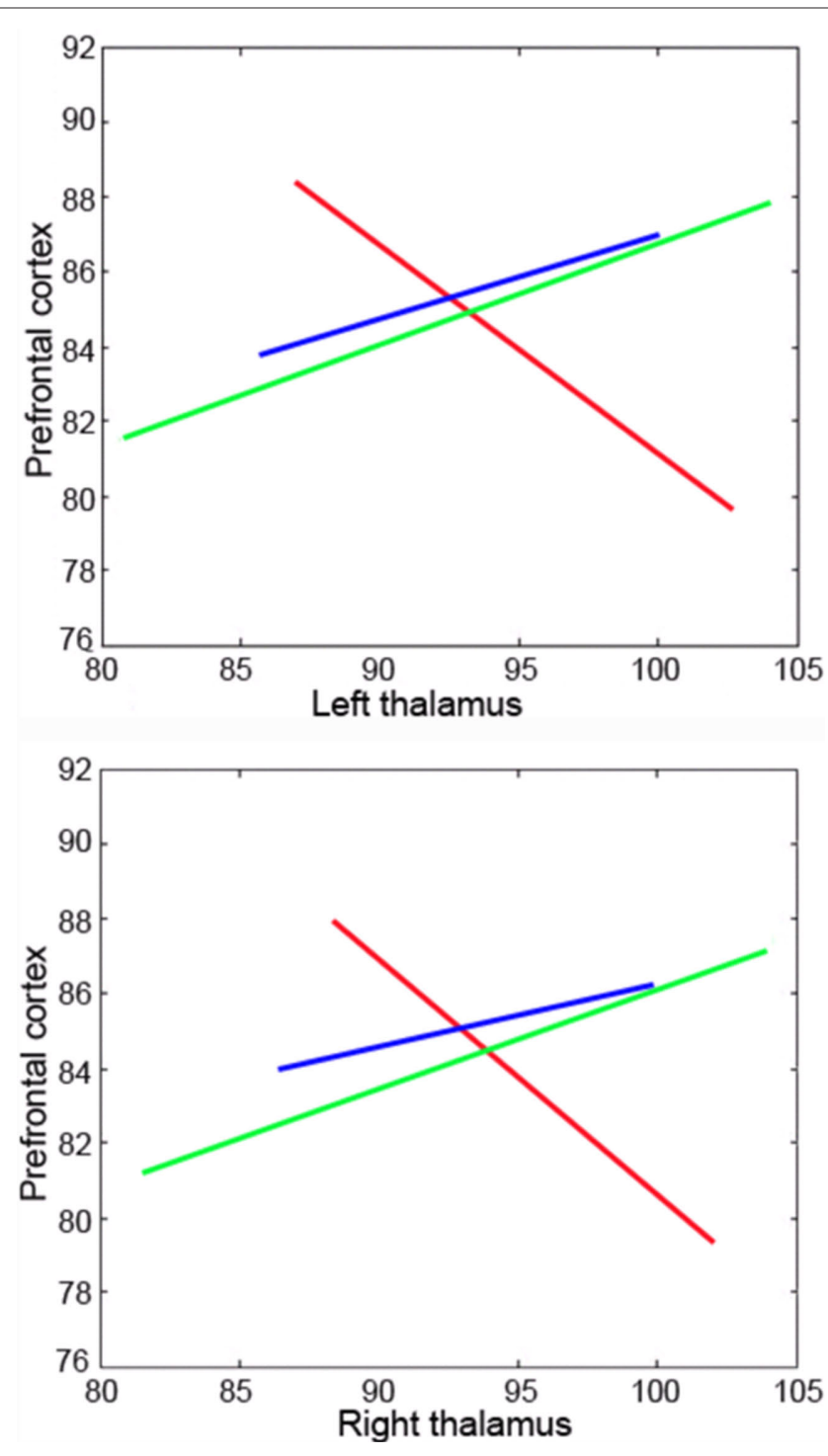

FIGURE 3 | Functional connectivity between the thalami and prefrontal cortex is abolished during pathological unconsciousness (UWS/VS; red regression line) and resumes a near-normal modulation after recovery of consciousness (blue line). The green line illustrates connectivity in healthy controls. Regression lines represent cross-correlation of normalized regional cerebral blood flow as measured by $\mathrm{H}_{2} \mathrm{O}^{15}$-PET. Adapted from Laureys et al. (2000b).

(Di et al., 2007) induced a widespread near-normal activation in MCS. The latter fMRI study also showed to be informative of patients' prognosis and recovery as confirmed by a recent study by Coleman et al. (2007).

\section{Active paradigms}

"Active paradigms" in neuroimaging studies, aiming to show command following, constitute a more direct proof to demonstrate conscious awareness, independent of motor activity. If a patient systematically follows a specific mental command, then this subject is expected to activate certain brain areas in a consistent manner and only then one can infer that this subject is conscious. Using this approach, a collaborative study between the Cambridge and Liège imaging centers, we showed in a clinically VS/UWS patient fMRI evidence of obeying to simple commands (i.e., "imagine walking around in your house" or "imaging playing tennis") in specific brain areas (i.e., parahippocampal and supplementary motor areas, respectively) indistinguishable from that observed in healthy controls (Owen et al., 2006). Such activation could not be attributed to automatic recruitment of these areas of interest (Soddu et al., 2009) and thus the patient was considered to be conscious. Of note is that 6 months later, when the patient was clinically re-examined, she recovered visual pursuit of a mirror (Vanhaudenhuyse et al., 2008), indicating her transition to a MCS. The residual brain activity detected via neuroimaging technologies could not be initially identified in the patient's bedside, suggesting that neuronal activation was taking place in absence of any behavioral output.

\section{STRUCTURAL IMAGING}

Structural connectivity refers to a network of physical or structural (axonal) connections which bines sets of neuronal populations. In clinical cases, information about the structural architecture of the brain can provide insights about recovery and neural plasticity in anoxic or traumatic brain injury. In chronic DOC, patients will progressively develop diffuse brain atrophy. In these cases, classical morphological MRI may not be a reliable indicator of the severity of the axonal injury and hence of the level of consciousness (Tshibanda et al., 2009). However, tools with higher sensitivity have been introduced which hold promise for studying plasticity in patients with DOC, such as diffusion tensor imaging (DTI) and magnetic resonance spectroscopy (MRS; Tshibanda et al., 2010).

Diffusion tensor imaging assesses the architectural organization of white matter fibers and hence can detect in vivo diffuse axonal injury (Arfanakis et al., 2002). In an exceptional case of late recovery from traumatic brain injury, Voss et al. (2006) used DTI to document an increased fractional anisotropy (thought to reflect fiber density) in large, bilateral regions of medial parieto-occipital areas of the white matter paralleling his clinical recovery of speech and motor function 19 years after the acute insult. These findings were contingent to an increased regional metabolism in these areas when measured with PET, similar to the partially restored cortical regions observed in patients who recover consciousness after being in a chronic VS/UWS (Laureys et al., 2000b, 2006a; Figure 5). This multimodal posteriomedial associative area has been previously suggested to be part of the human awareness network (Vogt and Laureys, 2005).

Magnetic resonance spectroscopy is another non-invasive technique that can provide in vivo quantification of certain biochemical markers such as $\mathrm{N}$-acetylaspartate (heralding information about neuronal density and viability), choline (reflecting cell membrane turnover), and creatine (reflecting cell aerobic energy metabolism; Tshibanda et al., 2009). When information from this technique was combined with morphological MRI in traumatic brain injury, patients could be separated in prognostic subgroups based on the Glasgow Outcome Scale which was not possible when the different imaging techniques were applied separately (Carpentier et al., 2006). 

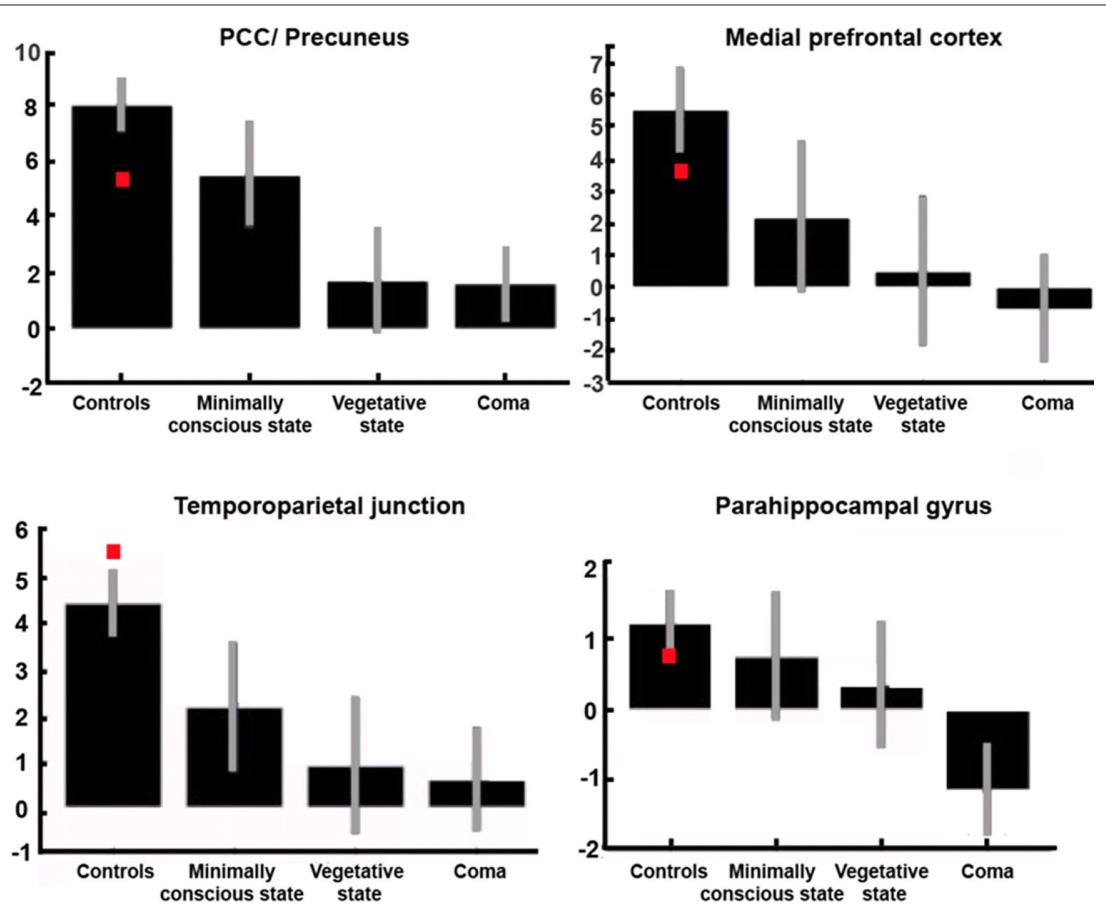

FIGURE 4 |The most representative nodes of the "default mode network" show a decrease in functional connectivity as we move from normal consciousness and locked-in syndrome (red squares) to minimally conscious or unconscious states. Graphs represent connectivity strength (mean $z$ scores with 90\% confidence intervals). PCC, posterior cingulate cortex. Adapted from Vanhaudenhuyse et al. (2009).
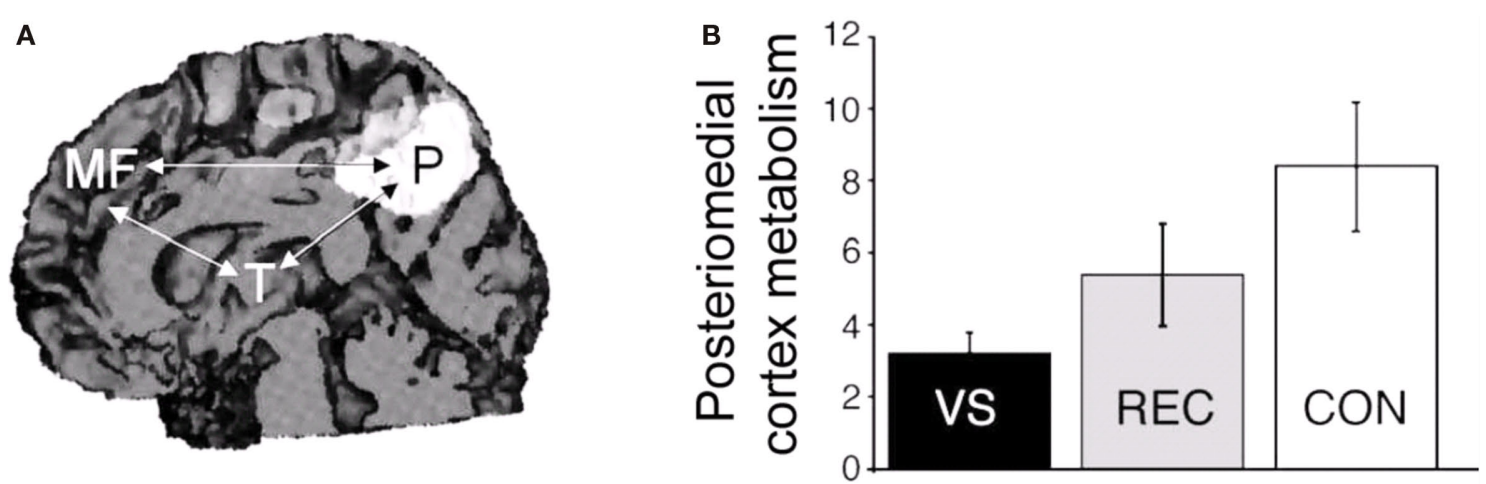

FIGURE 5 | (A) Restoration of glucose metabolism in posteriomedial cortices after recovery from the VS/UWS (area in white; arrows indicate the functional disconnections observed in VS/UWS patients). (B) In the same posteriomedial area, lower metabolism was observed in VS/UWS patients (black bar) as compared to those who recovered consciousness (gray bar) and to healthy controls (white bar), suggesting its critical role in the mediation of conscious awareness. Scale represents cerebral metabolic rates for glucose uptake (in mg/100 g/min). Adapted from Laureys et al. (2006a).

\section{PERSPECTIVES}

The use of resting state fMRI to study functional recovery and neural plasticity in DOC patients and its clinical routine use as a diagnostic and prognostic tool needs a controlled methodology and inclusion of a larger number of patients as is currently being tackled by multicentric collaborations. Nevertheless, clinicians should be aware of the many limitations and pitfalls intrinsic to "resting state" analyses - especially the challenge to disentangle genuine neural activity from artifactual movement-related fMRI signal in studies on severe brain injury (Soddu et al., in press). Although clinical assessment presently remains the gold standard in diagnosing this challenging population (Majerus et al., 2005), neuroimaging instruments in some exceptional cases of motor-deprived non-communicating DOC patients may be used as a means to establish a reliable communication code (Monti et al., 2010b). The challenge now will be to validate these novel technologies and to define the ethical and legal frameworks redefining cognitive competence in these patients with very limited and technology-dependent communication (Fins et al., 2008). Structural MRI coupled to spectroscopic and DTI techniques are currently being validated as prognostic markers in acute 
and chronic DOC (e.g., Lescot et al., 2009; Tshibanda et al., 2010). These studies also will improve our understanding of residual neural plasticity in the recovery of consciousness.

\section{CONCLUSION}

Most recoveries of consciousness, with or without recovery of social or professional integration, take place within the first 3 months after non-traumatic and after 12 months after traumatic cerebral accidents and survival beyond 10 years remains unusual - albeit depending on the level of medical and nursing care (The MultiSociety Task Force on PVS, 1994; Monti et al., 2010a). However, clinical cases of both late spontaneous recoveries (e.g., Voss et al., 2006; Estraneo et al., 2010) or after invasive interventional treatments (e.g., Schiff et al., 2007) challenge the dogma of temporally fixed periods for possible neuronal plasticity. It is important to stress that the cellular mechanisms underlying recovery of consciousness after severe brain damage remain speculative. Our understanding of possible neurogenesis (known to occur predominantly in associative fronto-parietal cortices in non-human primates; Gould et al., 1999), axonal sprouting and neurite outgrowth, or even apoptosis in this patient population remains very limited. The residual cerebral plasticity during vegetative/unresponsive and MCS

\section{REFERENCES}

Adams, J. H., Graham, D. I., and Jennett, B. (2000). The neuropathology of the vegetative state after an acute brain insult. Brain 123(Pt 7), 1327-1338.

Arfanakis, K., Haughton, V. M., Carew, J. D., Rogers, B. P., Dempsey, R. J., and Meyerand, M. E. (2002). Diffusion tensor MR imaging in diffuse axonal injury. Am. J. Neuroradiol. 23, 794-802.

Baars, B. J., Ramsoy, T. Z., and Laureys, S. (2003). Brain, conscious experience and the observing self. Trends Neurosci. 26, 671-675.

Boly, M., Balteau, E., Schnakers, C., Degueldre, C., Moonen, G., Luxen, A., Phillips, C., Peigneux, P., Maquet, P., and Laureys, S. (2007). Baseline brain activity fluctuations predict somatosensory perception in humans. Proc. Natl. Acad. Sci. U.S.A. 104, 12187-12192.

Boly, M., Faymonville, M. E., Peigneux, P., Lambermont, B., Damas, P., Del Fiore, G., Degueldre, C., Franck, G., Luxen, A., Lamy, M., Moonen, G., Maquet, P., and Laureys, S. (2004). Auditory processing in severely brain injured patients: differences between the minimally conscious state and the persistent vegetative state. Arch. Neurol. 61, 233-238.

Boly, M., Faymonville, M. E., Schnakers, C., Peigneux, P., Lambermont, B., Phillips, C., Lancellotti, P., Luxen, A., Lamy, M., Moonen, G., Maquet, P., and Laureys, S. (2008a). Perception of pain in the minimally conscious state with PET activation: an observational study. Lancet Neurol. 7 , 1013-1020.
Boly, M., Phillips, C., Tshibanda, L., Vanhaudenhuyse, A., Schabus, M., Dang-Vu, T. T., Moonen, G., Hustinx, R., Maquet, P., and Laureys, S. (2008b). Intrinsic brain activity in altered states of consciousness: how conscious is the default mode of brain function? Ann. N.Y. Acad. Sci. 1129, 119-129.

Boly, M., Tshibanda, L., Vanhaudenhuyse, A., Noirhomme, Q., Schnakers, C., Ledoux, D., Boveroux, P., Garweg, C., Lambermont, B., Phillips, C., Luxen, A., Moonen, G., Bassetti, C., Maquet, P., and Laureys, S. (2009). Functional connectivity in the default network during resting state is preserved in a vegetative but not in a brain dead patient. Hum. Brain Mapp. 30, 2393-2400.

Boveroux, P., Vanhaudenhuyse, A., Bruno, M. A., Noirhomme, Q., Lauwick, S., Luxen, A., Degueldre, C., Perlbarg, V., Plenevaux, A., Schnakers, C., Phillips, C., Brichant, J. F., Bohnomme, V., Maquet, P., Greicius, M. D., Laureys, S., and Boly, M. (2010). Breakdown of within- and between-network resting state functional magnetic resonance imaging connectivity during propofol-induced loss of consciousness. Anesthesiology 113, 1038-1053.

Bruno, M. A., Soddu, A., Demertzi, A., Laureys, S., Gosseries, O., Schnackers, C., Boly, M., Noirhomme, Q., Thonnard, M., Chatelle, C., and Vanhaudenhuyse, A. (2010). Disorders of consciousness: moving from passive to resting state and active paradigms. Cogn. Neurosci. 1, 193-203.

Buckner, R. L., Andrews-Hanna, J. R., and Schacter, D. L. (2008). The brain's default network: anatomy, function,

patients has been largely overlooked by the medical community and deserves further investigation. We believe that the challenge is now to identify the conditions in which and the mechanisms by which some patients may recover consciousness by use of the latest MRI and PET neuroimaging tools. The absence of large, controlled randomized interventional studies in patients with chronic DOC account for the present lack of evidence-based guidelines and tendency for therapeutic nihilism and can be related to the continuing societal, political, legal, and ethical debates in this field. The study of patients with chronic DOC may hence provide further insights in the medical management and rehabilitation of these patients at the clinical level, as well as increasing our understanding of the brain's long overlooked plastic abilities and the scientific quest for the neural correlates of human consciousness.

\section{ACKNOWLEDGMENTS}

This research was funded by the Belgian National Funds for Scientific Research (FNRS), the European Commission (DISCOS Marie-Curie Actions, COST, DECODER), the James McDonnell Foundation, the MindScience Foundation, the French Speaking Community Concerted Research Action (ARC-06/11-340), the Fondation Médicale Reine Elisabeth, and the University and University Hospital of Liège.

and relevance to disease. Ann. N.Y. Acad. Sci. 1124, 1-38.

Carpentier, A., Galanaud, D., Puybasset, L., Muller, J. C., Lescot, T., Boch, A L., Riedl, V., Cornu, P., Coriat, P., Dormont, D., and van Effenterre, R. (2006). Early morphologic and spectroscopic magnetic resonance in severe traumatic brain injuries can detect "invisible brain stem damage" and predict "vegetative states". J. Neurotrauma 23, 674-685.

Cohadon, F., and Richer, E. (1993). [Deep cerebral stimulation in patients with post-traumatic vegetative state. 25 cases]. Neurochirurgie 39, 281-292.

Coleman, M. R., Rodd, J. M., Davis, M.H., Johnsrude, I.S., Menon, D. K., Pickard, J. D., and Owen, A. M. (2007). Do vegetative patients retain aspects of language comprehension? Evidence from fMRI. Brain 130, 2494-2507.

Dehaene, S., Changeux, J. P., Naccache, L., Sackur, J., and Sergent, C. (2006). Conscious, preconscious, and subliminal processing: a testable taxonomy. Trends Cogn. Sci. 10, 204-211.

Demertzi, A., Soddu, A., Faymonville, M. E., Bahri, M. A., Gosseries, O., Vanhaudenhuyse, A., Phillips, C., Maquet, P., Noirhomme, Q., Luxen, A., and Laureys, S. (in press). Hypnotic modulation of resting state fMRI default mode and extrinsic network connectivity. Prog. Brain Res.

Demertzi, A., Vanhaudenhuyse, A. Bruno, M. A., Schnakers, C., Boly, M., Boveroux, P., Maquet, P., Moonen, G., and Laureys, S. (2008). Is there anybody in there? Detecting awareness in disorders of consciousness. Expert Rev. Neurother. 8, 1719-1730.
Di, H. B., Yu, S. M., Weng, X. C., Laureys, S., Yu, D., Li, J. Q., Qin, P. M., Zhu, Y. H., Zhang, S. Z., and Chen, Y. Z. (2007). Cerebral response to patient's own name in the vegetative and minimally conscious states. Neurology 68, 895-899.

Estraneo, A., Moretta, P., Loreto, V., Lanzillo, B., Santoro, L., and Trojano, L. (2010). Late recovery after traumatic, anoxic, or hemorrhagic longlasting vegetative state. Neurology 75 , 239-245.

Fins, J. J., Illes, J., Bernat, J. L., Hirsch, J., Laureys, S., and Murphy, E. (2008). Neuroimaging and disorders of consciousness: envisioning an ethical research agenda. Am. J. Bioeth. 8 , 3-12.

Friston, K. (2002). Beyond phrenology: what can neuroimaging tell us about distributed circuitry? Annu. Rev. Neurosci. 25, 221-250

Giacino, J. T., Ashwal, S., Childs, N., Cranford, R., Jennett, B., Katz, D. I., Kelly, J. P., Rosenberg, J. H., Whyte, J., Zafonte, R. D., and Zasler, N. D. (2002). The minimally conscious state: definition and diagnostic criteria. Neurology 58, 349-353.

Gould, E., Reeves, A. J., Graziano, M. S., and Gross, C. G. (1999). Neurogenesis in the neocortex of adult primates. Science 286, 548-552.

Jennett, B., and Plum, F. (1972). Persistent vegetative state after brain damage. A syndrome in search of a name. Lancet 1, 734-737.

Laureys, S. (2005). The neural correlate of (un)awareness: lessons from the vegetative state. Trends Cogn. Sci. 9, 556-559. 
Laureys, S., Celesia, G. G., Cohadon, F., Lavrijsen, J., Leon-Carrion, J., Sannita, W.G., Sazbon, L., Schmutzhard, E., von Wild, K. R., Zeman, A., and Dolce, G. (2010). Unresponsive wakefulness syndrome: a new name for the vegetative state or apallic syndrome. $B M C M e d .8$, 68. doi: 10.1186/1741-7015-8-68

Laureys, S., Faymonville, M. E., Degueldre, C., Fiore, G. D., Damas, P., Lambermont, B., Janssens, N., Aerts, J., Franck, G., Luxen, A., Moonen, G., Lamy, M., and Maquet, P. (2000a). Auditory processing in the vegetative state. Brain 123, 1589-1601.

Laureys, S., Faymonville, M. E., Luxen, A., Lamy, M., Franck, G., and Maquet, P. (2000b). Restoration of thalamocortical connectivity after recovery from persistent vegetative state. Lancet 355 , 1790-1791.

Laureys, S., Faymonville, M. E., Peigneux, P., Damas, P., Lambermont, B., Del Fiore, G., Degueldre, C., Aerts, J., Luxen, A., Franck, G., Lamy, M., Moonen, G., and Maquet, P. (2002). Cortical processing of noxious somatosensory stimuli in the persistent vegetative state. Neuroimage 17, 732-741.

Laureys, S., Boly, M., and Maquet, P. (2006a). Tracking the recovery of consciousness from coma. J. Clin. Invest. 116, 1823-1825.

Laureys, S., Giacino, J. T., Schiff, N. D., Schabus, M., and Owen,A.M. (2006b). How should functional imaging of patients with disorders of consciousness contribute to their clinical rehabilitation needs? Curr. Opin. Neurol. 19, 520-527.

Laureys, S., Goldman, S., Phillips, C., Van Bogaert, P., Aerts, J., Luxen, A., Franck, G., and Maquet, P. (1999). Impaired effective cortical connectivity in vegetative state: preliminary investigation using PET. Neuroimage 9, 377-382.

Laureys, S., Owen, A. M., and Schiff, N. D. (2004a). Brain function in coma, vegetative state, and related disorders. Lancet Neurol. 3, 537-546.

Laureys, S., Perrin, F., Faymonville, M. E., Schnakers, C., Boly, M., Bartsch, V., Majerus, S., Moonen, G., and Maquet, P. (2004b). Cerebral processing in the minimally conscious state. Neurology 63, 916-918.

Lescot, T., Galanaud, D., and Puybasset, L. (2009). Exploring altered consciousness states by magnetic resonance imaging in brain injury. Ann. N.Y. Acad. Sci. 1157, 71-80.

Lombardi, F., Taricco, M., De Tanti, A., Telaro, E., and Liberati, A. (2002). Sensory stimulation of brain-injured individuals in coma or vegetative state: results of a Cochrane systematic review. Clin. Rehabil. 16, 464-472.

Majerus, S., Gill-Thwaites, H., Andrews, K., and Laureys, S. (2005). Behavioral evaluation of consciousness in severe brain damage. Prog. Brain Res. 150, 397-413.

Mason, M. F., Norton, M. I., Van Horn, J. D., Wegner, D. M., Grafton, S. T., and Macrae, C. N. (2007). Wandering minds: the default network and stimulus-independent thought. Science 315, 393-395.

McGeown, W. J., Mazzoni, G., Venneri, A., and Kirsch, I. (2009). Hypnotic induction decreases anterior default mode activity. Conscious Cogn. 18, 848-555.

Monti, M. M., Laureys, S., and Owen, A. M. (2010a). The vegetative state. $B M J$ 341, c3765.

Monti, M. M., Vanhaudenhuyse, A., Coleman, M. R., Boly, M., Pickard,J.D., Tshibanda, L., Owen, A., and Laureys, S. (2010b). Willful modulation of brain activity in disorders of consciousness. N. Engl. J. Med. 362, 579-589.

Oh, H., and Seo, W. (2003). Sensory stimulation programme to improve recovery in comatose patients. J. Clin. Nurs. 12, 394-404.

Owen, A. M., Coleman, M. R., Boly, M., Davis, M. H., Laureys, S., and Pickard, J.D. (2006). Detecting awareness in the vegetative state. Science 313, 1402.

Passler, M. A., and Riggs, R. V. (2001). Positive outcomes in traumatic brain injury-vegetative state: patients treated with bromocriptine. Arch. Phys. Med. Rehabil. 82, 311-315.

Pistoia, F., Mura, E., Govoni, S., Fini, M., and Sara, M. (2010). Awakenings and awareness recovery in disorders of consciousness: is there a role for drugs? CNS Drugs 24, 625-638.

Sawyer, E., Mauro, L. S., and Ohlinger, M. J. (2008). Amantadine enhancement of arousal and cognition after traumatic brain injury. Ann. Pharmacother. 42, 247-252.

Schiff, N. D. (2010). Recovery of consciousness after brain injury: a mesocircuit hypothesis. Trends Neurosci. 33, 1-9.

Schiff, N. D., and Fins, J. J. (2007). Deep brain stimulation and cognition: moving from animal to patient. Curr. Opin. Neurol. 20, 638-642.

Schiff, N. D., Giacino, J. T., Kalmar, K., Victor, J. D., Baker, K., Gerber, M., Fritz, B., Eisenberg, B., O'Connor, J., Kobylarz, E. J., Farris, S., Machado, A., McCagg, C., Plum, F., Fins, J. J., and Rezai, A. R. (2007). Behavioural improvements with thalamic stimulation after severe traumatic brain injury. Nature 448, 600-603.

Schiff, N. D., Ribary, U., Moreno, D. R., Beattie, B., Kronberg, E., Blasberg, R., Giacino, J. T., McCagg, C., Fins, J. J., Llinas, R., and Plum, F. (2002). Residual cerebral activity and behavioural fragments can remain in the persistently vegetative brain. Brain 125, 1210-1234.

Schnakers, C., Hustinx, R., Vandewalle, G., Majerus, S., Moonen, G., Boly, M.,
Vanhaudenhuyse, A., and Laureys, S. (2008). Measuring the effect of amantadine in chronic anoxic minimally conscious state. J. Neurol. Neurosurg. Psychiatry 79, 225-227.

Shiel, A., Burn, J. P., Henry, D., Clark, J., Wilson, B. A., Burnett, M. E., and McLellan, D. L. (2001). The effects of increased rehabilitation therapy after brain injury: results of a prospective controlled trial. Clin. Rehabil. 15, 501-514.

Soddu, A., Boly, M., Nir, Y., Noirhomme, Q., Vanhaudenhuyse, A., Demertzi, A., Arzi, A., Ovadia, S., Stanziano, M., Papa, M., Laureys, S., and Malach, R. (2009). Reaching across the abyss: recent advances in functional magnetic resonance imaging and their potential relevance to disorders of consciousness. Prog. Brain Res. 177, 261-274.

Soddu, A., Vanhaudenhuyse, A., Bahri, M. A., Bruno, M. A., Boly, M., Demertzi, A., Tshibanda, J., Phillips, C., Stanziano, M., Ovadia-Caro, S., Nir, Y., Maquet, P., Papa, M., Malach, R., Laureys, S., and Noirhomme, Q. (in press). Identifying the default mode component in spatial ICA of patients with disorders of consciousness. Hum. Brain Mapp.

Taira, T., and Hori, T. (2007). Intrathecal baclofen in the treatment of poststroke central pain, dystonia, and persistent vegetative state. Acta Neurochir. Suppl. 97, 227-229.

The Multi-Society Task Force on PVS. (1994). Medical aspects of the persistent vegetative state (2).N. Engl. J. Med. 330, 1572-1579.

Tolle, P., and Reimer, M. (2003). Do we need stimulation programs as a part of nursing care for patients in "persistent vegetative state"? A conceptual analysis. Axone 25, 20-26.

Tononi, G., and Laureys, S. (2009). "The neurology of consciousness: an overview," in The Neurology of Consciousness: Cognitive Neuroscience and Neuropathology, eds S. Laureys and G. Tononi (Oxford, UK: Academic Press), 375-412.

Tshibanda, L., Vanhaudenhuyse, A., Boly, M., Soddu, A., Bruno, M. A., Moonen, G., Laureys, S., and Noirhomme, Q (2010). Neuroimaging after coma. Neuroradiology 52, 15-24.

Tshibanda, L., Vanhaudenhuyse, A., Galanaud, D., Boly, M., Laureys, S., and Puybasset,L. (2009). Magnetic resonance spectroscopy and diffusion tensor imaging in coma survivors: promises and pitfalls. Prog. Brain Res. 177, 215-229.

Vanhaudenhuyse,A., Demertzi,A., Schabus, M., Noirhomme, Q., Bredart, S., Boly, M., Phillips, C., Soddu, A., Luxen, A., Moonen, G., and Laureys, S. (2011). Two distinct neuronal networks mediate the awareness of environment and of self. J. Cogn. Neurosci. 23, 570-578.

Vanhaudenhuyse, A., Noirhomme, Q., Tshibanda, L. J., Bruno, M.A., Boveroux,
P., Schnakers, C., Soddu, A., Perlbarg, V., Ledoux, D., Brichant, J. F., Moonen, G., Maquet, P., Greicius, M. D., Laureys, S., and Boly, M. (2009). Default network connectivity reflects the level of consciousnessin non-communicative braindamaged patients. Brain 133, 161-171.

Vanhaudenhuyse, A., Schnakers, C., Bredart, S., and Laureys, S. (2008). Assessment of visual pursuit in postcomatose states: use a mirror. J. Neurol. Neurosurg. Psychiatry 79, 223.

Vogt, B. A., and Laureys, S. (2005). Posterior cingulate, precuneal and retrosplenial cortices: cytology and components of the neural network correlates of consciousness. Prog. Brain Res. 150, 205-217.

Voss, H. U., Uluc, A. M., Dyke, J. P., Watts, R., Kobylarz, E. J., McCandliss, B. D., Heier, L. A., Beattie, B. J., Hamacher, K. A., Vallabhajosula, S., Goldsmith, S.J., Ballon, D., Giacino, J.T., and Schiff,N.D. (2006). Possible axonal regrowth in late recovery from the minimally conscious state. J. Clin. Invest. 116, 2005-2011.

Whyte,J., Katz, D., Long, D., DiPasquale, M. C., Polansky, M., Kalmar, K., Giacino, J. T., Childs, N., Mercer, W., Novak, P., Maurer, P., and Eifert, B. (2005). Predictors of outcome in prolonged posttraumatic disorders of consciousness and assessment of medication effects: a multicenter study. Arch. Phys. Med. Rehabil. 86, 453-462.

Yamamoto, T., Katayama, Y., Oshima, H., Fukaya, C., Kawamata, T., and Tsubokawa, T. (2001). Deep brain stimulation therapy for a persistent vegetative state. Acta Neurochir. Suppl. 79, 79-82.

Conflict of InterestStatement:The authors declare that this research was conducted in the absence of any commercial or financial relationships that could be construed as a potential conflict of interest.

Received: 16 October 2010; paper pending published: 19 November 2010; accepted: 24 December 2010; published online: 07 February 2011.

Citation: Demertzi A, Schnakers C, Soddu A, Bruno M-A, Gosseries O, Vanhaudenhuyse A and Laureys S (2010) Neural plasticity lessons from disorders of consciousness. Front. Psychology 1:245. doi: 10.3389/fpsyg.2010.00245

This article was submitted to Frontiers in Consciousness Research, a specialty of Frontiers in Psychology.

Copyright (๑) 2011 Demertzi, Schnakers, Soddu, Bruno, Gosseries, Vanhaudenhuyse and Laureys. This is an open-access article subject to an exclusive license agreement between the authors and Frontiers Media $S A$, which permits unrestricted use, distribution, and reproduction in any medium, provided the original authors and source are credited. 